\title{
ACOMPANHANDO A CONSTRUÇÃO DO DESENHO DOS CENTROS COMUNITÁRIOS DE PRODUÇÃO DA ELETROBRAS: DA GERAÇÃO DE RENDA AO INCREMENTO DE CAPITAL SOCIAL
}

\author{
FOLLOWING THE CONSTRUCTION OF THE DESIGN FROM THE \\ COMMUNITY CENTERS PRODUCTION OF ELETROBRAS: FROM THE \\ INCOME GENERATION TO THE INCREASE OF THE SOCIAL CAPITAL
}

\author{
Nilton Cesar Santos ${ }^{1}$ e André Augusto Pereira Brandão 2
}

Recebido em: 08/05/2015

Aprovado em: 22/01/2016

\section{RESUMO}

O presente trabalho pretende analisar alguns documentos utilizados para a consolidação do Projeto dos Centros Comunitários de Produção (CCPs) da Eletrobras e identificar, especialmente, como o conceito de capital social foi incorporado no discurso e nos processos desenvolvidos na formatação e formalização dos primeiros projetos. Partindo de uma concepção mais ampla em que "documento" é considerado em termos de campos, de estruturas e de redes de ação, representando uma versão específica de realidades construídas para objetivos específicos, foram analisados um conjunto de sete documentos. Como critérios para a escolha dos documentos, foram considerados a autenticidade, credibilidade, representatividade e significação. A análise é apresentada de forma cronológica a partir de documentos produzidos entre 2003 e 2007, tendo abrangência interna e externa à Eletrobras. Observou-se que elementos propulsores de capital social são introduzidos em quase todos os documentos analisados. Mesmo em matérias informativas, de veiculação interna da empresa, os CCPs foram apresentados como projetos que, além de gerar renda, transformam realidades sociais em direção a formatos de protagonismo associativo local, impulsionando indivíduos e grupos a buscarem mudança por meio da confiança e da participação.

Palavras-chave: Centros Comunitários de Produção; Capital Social; Análise Documental.

\begin{abstract}
This paper intends to analyze some documents used for the consolidation of the Community Center Production Project (CCP) from Eletrobras and to identify, specially, how the concept of social capital has been incorporated into the discourse and processes developed in formatting and formalization of the first projects. From a broader conception in which "document" is considered in terms of fields, structures and action networks, representing a particular version of the reality constructed for specific purposes, we analyzed a set of seven documents. As criteria for the choice of the documents were considered the authenticity, credibility, representativeness and meaning. The analysis is presented in chronological order from documents produced between 2003 and 2007, with internal and external reach to Eletrobras. It was observed that elements that propitiate social capital are introduced in almost all the analyzed documents. Even in informative materials, from internal transit in the company, CCPs were presented as projects that beyond generating income, also transform social realities in direction to the formats of local social protagonism, propelling individuals and groups to seek change through trust and participation.

Keywords: Community Centers Production; Social Capital; Documental Analysis.
\end{abstract}

\footnotetext{
' Doutorando em Política Social pela Universidade Federal Fluminense (UFF), Brasil. E-mail: nilton.santos@eletrobras.com.

${ }^{2}$ Professor Associado do Programa de Estudos Pós-Graduados em Política Social da Universidade Federal Fluminense (UFF), Brasil. E-mail: aapbuff@ globo.com.
} 


\section{Introdução}

O conceito de capital social extraído da obra de Putnam (2007) é utilizado neste artigo como ferramenta para a análise de um conjunto de documentos que nortearam o início do projeto dos Centros Comunitários de Produção (CCPs), implementado pela Eletrobras - Centrais Elétricas Brasileiras. Esse projeto nasceu em 2003 atrelado ao Programa Nacional de Eletrificação Rural Luz no Campo, que foi lançado no governo de Fernando Henrique Cardoso, por meio de um decreto publicado no Diário Oficial de 03 de dezembro de 1999, seção 1, p. 108, v. 137, n. 231. Coordenado pelo Ministério de Minas e Energias, foi operacionalizado pela Eletrobras.

Atualmente, a Eletrobras conta com 23 CCPs instalados nas regiões Nordeste, Sul, Sudeste e Centro-Oeste, atendendo em torno de 1.230 famílias de agricultores. As atividades desenvolvidas pelos CCPs são variadas: resfriamento de leite, fabricação de farinha de mandioca, processamento de tomate, produção de doces e compotas de frutas, fabricação de rapadura e açúcar mascavo, produção de suco de uvas e processamento de hortaliças e legumes.

O objetivo do programa Luz no Campo era atingir as áreas rurais que careciam de atendimento de energia elétrica e, consequentemente, promover a melhoria das condições de vida de áreas mais isoladas do país. Para as regiões Norte, Nordeste e Centro-Oeste, foi previsto um tratamento diferenciado no que tange aos prazos e às condições de financiamentos, em razão de seu baixo índice de eletrificação rural.

A partir dos resultados de uma pesquisa de âmbito nacional, contratada pela Eletrobras para verificar os impactos causados pelo programa Luz no Campo, pôde-se identificar que a utilização da energia nessas novas áreas se destinava apenas para fins domésticos. A fim de criar oportunidades de geração de renda e atribuir uma finalidade pro- dutiva para esse novo insumo disponível a essas comunidades, a Eletrobras desenvolveu o projeto dos CCPs em 2003, no final da vigência do programa Luz no Campo e no início do programa Luz para Todos, lançado em novembro de 2003, já no governo do presidente Luiz Inácio Lula da Silva.

Os CCPs são unidades compostas por um conjunto de máquinas e equipamentos para produção, processamento, conservação e/ou armazenagem de produtos agropecuários. Buscam empregar tecnologias apropriadas e utilizar energia elétrica de maneira eficiente. Em termos de instalações, os CCPs podem ser pequenas estruturas, galpões ou qualquer tipo de edificação que atenda às exigências legais, sanitárias e ambientais e aos demais requisitos técnicos.

Um CCP nasce de parcerias. A Eletrobras, além do aporte financeiro para a compra dos equipamentos utilizados no empreendimento, encarregase da gestão do processo de implantação, da articulação junto aos parceiros e do monitoramento do projeto. Como demais parceiros, existem o poder público municipal, que geralmente contribui com a doação do material para a edificação da unidade e com um engenheiro para acompanhar a obra; o órgão de extensão rural, que pode ser de nível municipal ou estadual e fica responsável por prestar assistência técnica; a concessionária de distribuição de energia elétrica $^{3}$, que se responsabiliza pela instalação elétrica da unidade e dos equipamentos; e a associação comunitária, que reúne os agricultores familiares ${ }^{4}$ que serão beneficiados e fornece a mão de obra para a construção da unidade.

O projeto dos CCPs prevê que as comunidades contempladas com a inicia-

${ }^{3}$ Refere-se às empresas que fazem a comercialização de energia entre a unidade consumidora e a unidade transmissora. Exemplo: Light, Ampla e Cemig. Agente titular de concessão, permissão ou autorização federal para explorar a prestação de serviços públicos de energia elétrica. Encontrado em [http://www.aneel gov br//biblioteca/glossario $\mathrm{cfm}$ ?att=C)] 4 A gricultura familiar é uma forma de producão em que predoñ a A a rigem o processo produtivo, dando ênfase à diversificação e utilizando o trabalho familiar como fonte de renda, eventualmente complementada pelo trabalho assalariado. Encontrado em [http://www.mds.gov.br/ falemds/perguntas-frequentes/bolsa-familia/programas-complementares beneficiario/agricultura-familiar)]. 
tiva tenham uma formação associativa e possuam uma vocação produtiva. Para a Eletrobras, é importante que o projeto seja resultado de um processo endógeno em que a comunidade esteja presente em todas as fases, desde seu início, como mais um dos protagonistas da ação.

Diante disso, busca-se neste artigo identificar como o conceito de capital social se conforma nos discursos apresentados nos documentos formais ou informais utilizados pelos agentes desde o início da formulação do projeto. Ou seja, trata-se de analisar em que medida um projeto que visa à geração de renda por meio de atividades comunitárias entre agricultores familiares se relaciona com perspectivas ligadas ao conceito de capital social.

Putnam (2007) entende capital social como um conjunto de práticas sociais e sistemas de participação que fomentam a cooperação. Para Putnam (2007), quanto maior a relação de confiança existente entre indivíduos de determinado grupo social, maior serão seu capital social e suas possibilidades de associação.

Um conceito mais amplo de capital social está vinculado ao valor tácito que a participação em uma rede social pode atribuir a partir das relações estabelecidas interna e externamente a essa rede. Tratase da rede social como um valor econômico. Dependendo dos contatos sociais e da forma como estes são realizados, eles poderão ser fator de desenvolvimento econômico. Da mesma forma que um equipamento de trabalho pode aumentar a produtividade, as relações sociais também geram capital (Putnam, 2007).

Em seu livro "Comunidade e Democracia: a experiência da Itália moderna", Putnam (2007) avalia a continuidade e as mudanças institucionais ocorridas na Itália durante um período de vinte anos. O autor constata que as diferenças entre regiões tinham raízes históricas que remetiam a aspectos fundamentais da democracia, do desenvolvimento econômico e da vida cívica. Em seu estudo, Putnam (2007) demonstra de que modo a "comunidade cívica", ou seja, os padrões de participação cívica e de solidariedade social, podem ser uma das possibilidades para explicar o que diferencia as regiões do Norte da Itália, com bom desempenho institucional, das regiões do Sul, com mau desempenho.

A igualdade política, que implica direitos e deveres iguais para todos, é apontada por Putnam (2007) como um dos elementos de civismo. Por meio de relações horizontais de reciprocidade $\mathrm{e}$ cooperação, em detrimento de relações verticais de autoridade e dependência, mantém-se a comunidade unida. Putnam (2007) também chama a atenção para os estoques de solidariedade, de confiança e de tolerância como outros elementos que fazem com que os cidadãos em uma comunidade cívica mantenham elevados níveis de cooperação entre si.

As associações enquanto estruturas sociais da cooperação aparecem como mais um elemento que contribui para gerar efeitos sobre os indivíduos e sobre a sociedade, incorporando e reforçando normas e valores comunitários. Tais achados de Putnam (2007) se configuram como parâmetros que buscamos contrapor, neste estudo, aos documentos analisados para pensar se as ações de geração de renda desenvolvidas entre agricultores familiares podem promover ganho de capital social.

Assim, podemos perguntar: o desenho do projeto que dá origem à implementação dos CCPs da Eletrobras propicia a instauração de relações de confiança mútua, participação e práticas associativistas? Os documentos que acompanham a dinâmica de implementação do projeto apresentam ou sinalizam em seus discursos essas possibilidades? Estas são questões que o artigo se propõe a analisar, identificando de que modo e por meio de quais atores esse discurso se materializa. 


\section{Método e referencial teórico}

Segundo Flick (2009), a análise documental deve ser constituída de um corpus, ou seja, de uma amostra de documentos que possa representar significativamente todo o conjunto que se escolheu analisar. Entretanto, nosso objetivo foi selecionar documentos de forma proposital para o entendimento de um caso específico. Nesse contexto, Flick (2009) chama a atenção para o problema da intertextualidade, isto é, das conexões que um documento pode ter com outros documentos, fazendo referências ao modo como estes constroem a realidade social. Para Flick (2009), observar e considerar tais conexões podem ser atitudes úteis para $o$ estudo. No caso dos documentos aqui analisados, houve a preocupação em verificar as conexões cronológicas entre documentos, averiguando se haveria uma continuidade no discurso ao longo do tempo e se um documento contribui para ratificar o que o documento anterior propôs. Além disso, houve também a preocupação em entender o envolvimento e o interesse dos autores desses documentos em sua produção.

Documentos não são produzidos apenas como demonstração de fatos ou realidades. Quem os produz busca atingir algum objetivo prático (Flick, 2009). Nessa perspectiva, o autor aponta uma série de questionamentos que devem ser considerados pelo analista em uma análise de documentos.

Especificamente em relação a este trabalho, não pretendemos esgotar as possibilidades analíticas passíveis de serem verificadas nos documentos selecionados. Portanto, foram traçadas algumas perguntas utilizadas como referência para o desenvolvimento do estudo. Cabe ressaltar que o processo analítico não foi pautado apenas em destacar os elementos expostos nos documentos, pois a facilidade de acesso ao objeto, a experiência e o envolvimento dos autores deste artigo com o projeto de CCP facilitaram a compreensão do contexto no qual os documentos foram produzidos. Assim, acreditamos que: "Os documentos devem ser vistos como uma forma de contextualização da informação" (Flick, 2009).

Ao trabalhar com tais documentos, nosso interesse está voltado para compreender: a) como tem origem o projeto dos CCPs; b) quais as justificativas para a existência de um projeto de geração de renda capitaneado por uma empresa de energia elétrica; c) como tal projeto foi articulado institucionalmente; d) como se configuraram normativamente os arranjos políticos que ensejaram a implementação do projeto; e) em que cenário político o projeto se alavancou ou foi construído; e, principalmente, f) se traços componentes do conceito de capital social permeavam o discurso dos formuladores da ação na época.

Nesse sentido, as concepções desenvolvidas nos documentos serão cotejadas com o conceito teórico de capital social. Vale ressaltar que, tomando como base a obra de (Putnam, 2007), esse conceito se refere a práticas associativas horizontais e normas sociais de confiança intersubjetiva que se estabelem entre os cidadãos e que otimizam o engajamento cívico.

Frente aos objetivos por nós propostos, a análise documental é fundamental, pois permite entender o contexto político em que se insere o projeto e os conceitos que estão norteando esse contexto, bem como os valores e as posições preconizados pelos atores envolvidos. Possibilita, ainda, identificar quem são os atores formuladores e auxilia a compreender as relações de poder que atravessam suas relações.

Embora o termo "documento" seja mais comumente definido como artefatos padronizados, tais como notas, contratos e certidões, trabalhamos neste artigo com um conceito mais amplo, que entende que os documentos devem ser considerados como elementos correlatos a estruturas de sentido e de ação (Prior, 2003, apud Flick, 2009). 
Partindo desse conceito, foram observados 11 documentos, dos quais quatro não apresentavam qualquer componente que contribuísse, de forma específica, para a proposta deste estudo e, portanto, foram descartados. Por fim, um conjunto de sete documentos, baseados no conceito mais amplo de Prior (2003), foram efetivamente analisados. Estes correspondem a: um manual, dois relatórios, duas matérias jornalísticas e duas propostas de projeto. Quanto à qualidade dos documentos, seguimos a orientação de Scott (1990), que sugere a apreciação de quatro critérios a serem considerados para a escolha de um documento: autenticidade, credibilidade, representatividade e significação.

Finalizando esta descrição metodológica, reafirmamos que o presente artigo pretende analisar alguns documentos utilizados para a consolidação do projeto dos CCPs da Eletrobras e identificar, especialmente, como o conceito de capital social foi incorporado no discurso e nos processos desenvolvidos na formatação e formalização dos primeiros projetos. A análise será apresentada de forma cronológica para que seja possível entender como as mudanças ocorreram ao longo do tempo no desenho do projeto. Os documentos analisados foram produzidos entre 2003 e 2007, tendo abrangência interna e externa à Eletrobras.

\section{Apresentação e discussão dos resul- tados}

A consolidação dos CCPs: uma análise a partir da documentação

$\mathrm{O}$ primeiro documento analisado data de $1^{\circ}$ de janeiro de 2003 e referese a uma minuta que criou, qualificou e propôs os CCPs como um projeto que deveria ser adotado pela Eletrobras. Essa minuta se intitulava: "Luz no Campo - Projetos Sustentáveis Proposta de Projeto". Trata-se de um documento interno, produzido pelo Departamento de Engenharia de Distribuição, que era o espaço institucional responsável na época pela operacionalização do Programa Luz no Campo e pela defesa de uma proposta de projetos sustentáveis atrelada ao Programa de Universalização do fornecimento de energia elétrica.

O documento faz uma abordagem sobre os "Projetos Sustentáveis", apresentando-os como um caminho possível para vencer as barreiras que o meio rural enfrenta para gerar renda e se desenvolver economicamente. Ademais, apresenta os entraves encontrados na época para levar a energia elétrica a essas áreas: alta dispersão e baixo consumo, o que acabava por não tornar atrativo para as concessionárias esse segmento da sociedade.

A falta de atratividade do meio rural para as concessionárias aparece no documento como um motivo importante para que houvesse o apoio da Eletrobras a partir de sua Diretoria Executiva - instância responsável na empresa pela aprovação de projetos. Para as concessionárias, era importante que as novas propriedades rurais ligadas à rede elétrica tivessem condições de pagar a conta do fornecimento de energia e os custos de instalação. No documento analisado, é possível perceber que, mesmo havendo menção às possibilidades de promoção social que o projeto realiza, a justificativa para sua institucionalização está baseada no retorno econômico que o mesmo pode promover a partir da implementação de tecnologias que vão possibilitar aos agricultores familiares deixar a produção artesanal e atingir patamares de maior escala de produção. Esse incremento fomentaria um mercado rural de energia, cuja demanda viria tanto das novas atividades produtivas quanto do consumo doméstico, gerando, concomitante, conforto e benefícios econômicos para as famílias, além de uma maior garantia de adimplência para as concessionárias.

Lançando mão de resultados parciais de uma pesquisa sobre o Programa 
Luz no Campo, o documento reforça a necessidade de desenvolver projetos de geração de trabalho e renda que possibilitem a fixação dos agricultores familiares na zona rural. Esse documento, cujo texto é uma minuta do projeto de CCP, aponta os resultados que o projeto é capaz de produzir para os agricultores rurais a partir dos possíveis ganhos financeiros. Nessa perspectiva, o aumento de renda é um fator de importância que propiciará as condições de adimplência, de melhoria de vida do produtor e de continuidade das unidades produtivas.

Outro ponto destacado pelo documento é relativo ao estabelecimento de parcerias. Alguns exemplos de parceiros e seus papéis são, portanto, apresentados. No projeto, a Eletrobras assumiria a gestão do processo de implantação e buscaria desenvolver meios para levar a esse "homem do campo" subsídios e apoio técnico que o estimulasse a conquistar sua sustentabilidade econômica.

Quando no documento são discutidos os objetivos do projeto, é possível notar a forte valoração atribuída ao aumento de renda das famílias, a viabilização do uso de máquinas na produção, a preocupação em estimular formas de comercialização dos produtos beneficiados, a redução do êxodo rural e a preocupação em destacar que o projeto promove a viabilização de um mercado rural de energia elétrica - argumento utilizado para chamar a atenção das concessionárias de distribuição para a zona rural como um nicho de mercado.

$\mathrm{O}$ documento destaca a formação de parcerias entre empresas e instituições e o trabalho coletivo dos agricultores familiares como meios utilizados para atingir um objetivo comum. Podemos considerar que componentes do conceito de capital social estão sendo esboçados no documento de uma forma subliminar. Para que haja parceria e participação, é necessário existir, na articulação entre os próprios produtores e entre eles e os demais parceiros, uma relação de confiança mútua. Obviamen- te, essa relação de confiança não é uma condição sine qua non, mas pode surgir com o tempo, na medida em que tais grupos vão trabalhando em conjunto $\mathrm{e}$ estabelecendo uma relação de troca. A cooperação e a confiança são tratadas por Putnam (2007) como uma via de mão dupla, pois, ao mesmo tempo em que a confiança gera possibilidades de cooperação, as bem-sucedidas experiências cooperativas, ao serem continuamente repetidas, realimentam as bases da confiança.

Esse mesmo documento deixa claro o vínculo do projeto de CCP com o Programa Luz no Campo. Tal relação aparece no documento como pré-requisito para as comunidades pleitearem sua participação: estas devem ser atendidas pelo Programa ou nele estar cadastradas. Nessse sentido, o documento preocupa-se em apresentar os objetivos do Programa Luz no Campo, o que ele representa enquanto um programa de eletrificação rural e os recursos que foram destinados para sua realização. $\mathrm{O}$ Programa Luz no Campo é identificado no documento como um projeto do responsabilidade social. Nesse ponto, os mentores do documento reforçam e fundamentam o caráter do projeto de CCP, em consonância e de forma complementar ao projeto maior de universalização da energia elétrica.

O documento também classifica os CCPs como um dos projetos, de um total de três, contidos em um projeto original chamado "Luz no Campo - Projetos Sustentáveis". Esse projeto maior visava ampliar as ações do Programa Luz no Campo, desenvolvendo, além dos CCPs, projeto para capacitação da comunidade beneficiada (identificado por "Treinamento") e projeto de transferência de conhecimento de forma mais prática para técnicos que atuariam diretamente com os agricultores familiares (identificado como "Centro de Demonstração").

O projeto de CCP não dispunha de recursos financeiros para sua implantação. No entanto, há um item no documento que 
menciona ganhos ocorridos em 2002 que fortaleceriam a implementação do "Luz no Campo - Projetos Sustentáveis”. Esses ganhos dizem respeito a recursos que foram previstos pelo Programa Luz no Campo para que as concessionárias promovessem a divulgação do Programa. Porém, tais recursos passariam a ser utilizados também no custeio de projetos voltados para o aumento da produção agrícola local. Ou seja, o projeto de CCP passaria a contar com recursos da Reserva Global de Reversão (RGR) a partir da alteração da cláusula $17^{5}$ dos contratos de financiamento do Programa Luz no Campo, firmados entre a Eletrobras e as concessionárias de distribuição de energia elétrica.

Embora o projeto CCP tenha iniciado sem recursos alocados para sua execução, esse documento analisado, que é a minuta do projeto, encarregase de apresentar os caminhos possíveis para a obtenção de tais recursos dentro da própria empresa. Visto que seriam os agricultores familiares que teriam de arcar com as contas de consumo de energia, além das parcelas do financiamento da extensão de rede e da montagem do padrão de medição executados pelas concessionárias em suas propriedades, o projeto de CCP aparece como uma estratégia cabível para que os agricultores possam gerar renda e garantir o pagamento desses serviços e, por conseguinte, o retorno dos empréstimos realizados pela Eletrobras às concessionárias para a execução do Programa Luz no Campo.

Como podemos verificar, o projeto de CCP não foi uma ação idealizada de cima para baixo, partindo da diretoria da Eletrobras. Refere-se a uma proposta de instâncias medianas, no nível de departamento $^{6}$, visando a uma ampliação de suas ações e atendendo a uma previsão do Programa Luz no Campo no intuito de fomentar políticas sociais. Esse sentido inverso da proposta de ação, que

${ }^{5}$ Cláusula do Contrato de financiamento do Programa Luz no Campo que prevê o recolhimento de parte dos valores concedidos em uma cont de investimento, destinada a cobrir despesas relativas à divulgação do Programa

${ }^{6} \mathrm{Na}$ Eletrobras existem três níveis hierárquicos abaixo do nível de diretoria: Superintendência, Gerência de Departamento e Gerência de Divisão. parte de baixo para cima, pode ser um dos fatores para entender a fragilidade enfrentada pelo projeto nos dias de hoje e a dificuldade em transformá-lo em uma ação que faça parte do rol de compromissos estratégicos da empresa.

Como elementos que apontam para aspectos mais diretamente ligados ao conceito de capital social, pode-se destacar as exigências que o documento apresenta para o processo de implantação de um CCP que, em tese, conduziriam para a geração de capital social: a participação efetiva dos produtores por meio de uma associação; sua articulação com instituições públicas, propiciando a abertura de um canal de comunicação para a busca futura de novos projetos voltados para melhorias comunitárias; e o reforço dos vínculos comunitários e das regras de reciprocidade. Entretanto, é possível entender a falta de elementos expostos claramente no texto que apontem para esses aspectos, visto que o mote principal do projeto fora, inicialmente, a geração de renda.

$\mathrm{O}$ segundo documento analisado refere-se ao manual criado pela Eletrobras para orientar os proponentes a apresentarem seus projetos de CCP. O manual foi lançado em 15 de julho de 2003, no governo de Luiz Inácio Lula da Silva. Por o projeto de CCP ser atrelado ao Programa Luz no Campo, esse documento faz uma introdução descrevendo o acesso à energia como meio de promover conforto, modernização, transformação de matérias-primas em bens manufaturados e, consequentemente, geração de renda. Ainda na introdução do documento, é apontada a necessidade de pensar em alternativas para as famílias que passam a receber energia elétrica tenham a possibilidade de agregar valor aos insumos agrícolas produzidos em suas propriedades a fim de gerar excedentes financeiros e, consequentemente, possibilitar o pagamento de suas contas de energia. Também na introdução do manual, foi mencionada a necessidade de implantação dos CCPs em comuni- 
dades onde a produção dos agricultores familiares pudesse ser desenvolvida por meio de procedimentos coletivos e/ou associativos, o que possibilitaria a geração de uma escala de produção capaz de justificar o investimento.

O discurso relativo ao associativismo, um dos elementos apontados por Putnam (2007) como componente fundamental do capital social, da mesma forma que no primeiro documento analisado, é ratificado aqui quando são descritas no texto as exigências para a implantação de um CCP. Para Putnam (2007), a afiliação a grupos que buscam uma organização horizontalizada, como clubes desportivos, cooperativas, associações etc., propicia um bom desempenho no nível da gestão. No manual, para que um CCP seja implantado, é exigido que os agricultores familiares se organizem em uma associação. Ou seja, a ideia é que o CCP gere renda, a partir de esforços combinados. Fica claro, assim, que a preocupação do formulador do manual com o trabalho coletivo não se deve à possibilidade de desenvolver a participação ou fomentar no espaço rural regras de reciprocidade. Contudo, na perspectiva de Putnam (2007), a cooperação é tão mais sólida quanto maior for a compreensão acerca de sua importância objetiva pelos participantes. Ao exigir no manual a formação da associação para o pleito de um CCP, a Eletrobras contribui indiretamente para ajudar a encaminhar esses agricultores na direção de um movimento para a cooperação.

A cooperação não seria o produto, necessariamente, de uma ética de união entre os homens, mas de uma permuta de interesses convergentes. Nessa perspectiva, entende-se que o interesse de cada agricultor também é o interesse de todos juntos e que, a partir desse esforço de cooperação o desejo individual pode ser mais fácil de ser atingido. Tal perspectiva seria um estímulo para os agricultores mais participativos e criaria uma situação modelo, passível de ser seguida por aqueles menos dispostos à ação coletiva.
Teríamos aí um "interesse próprio que é 'esclarecido' e não 'míope'. O interesse próprio que é sensível aos interesses dos outros", chamado por Tocqueville (2004) de "interesse próprio corretamente entendido" (Putnam, 2007, p. 102). Entretanto, para que os agricultores tenham esclarecidos e corretamente entendidos os interesses em jogo, seria importante a realização do projeto de "Treinamento" citado no primeiro documento, que prevê a capacitação dos beneficiários, considerando em seu escopo conceitos de cooperação, participação e associativismo.

Esse documento, além de definir os papéis das principais instituições com potencial para parceria, cumpre sua função de manual apresentando o roteiro para a formulação dos projetos para proposição de CCPs que deveriam ser produzidos por associações comunitárias de agricultores familiares. No que tange ao grupo de possíveis beneficiários, o manual define um conjunto de exigências: "A associação deve ser constituída por um número mínimo de $80 \%$ de pequenos produtores da comunidade que utilizem mão de obra predominantemente familiar". Além disso, o manual indica que as associações proponentes de projetos de CCP devem assumir o compromisso de informar aos participantes e beneficiários todas as decisões e discutir com estes a definição das responsabilidades.

$\mathrm{O}$ terceiro documento analisado foi produzido em 10 de dezembro de 2003 e consiste em um relatório de atividades do funcionário da Eletrobras responsável pela implantação do projeto. Esse documento relata todo o processo de implantação do primeiro CCP da Eletrobras, em São Fidélis, Rio de Janeiro, destacando desde os diálogos iniciais com os agricultores familiares e parceiros até sua inauguração. Descreve os gastos despendidos por cada parceiro, sem contabilizar os custos indiretos e cita os papéis de cada parceiro: Associação de Produtores local; Empresa de Assistência Técnica e Extensão Rural 
do Estado do Rio de Janeiro- (Emater-RIO); Prefeitura Municipal de São Fidélis; Companhia de Eletricidade do Rio de Janeiro (CERJ), atual AMPLA; e Eletrobras. O documento apresenta um item de conclusões, apontando problemas encontrados na construção do CCP de São Fidélis - a ineficiência e falta de compromisso dos funcionários da prefeitura, impactando na execução das obras, são evidenciadas no relatório.

Esse relatório constitui um documento que se centra em apresentar o processo de edificação da unidade - o que é compreensível pelo fato de ter sido redigido por um engenheiro que indica os elementos do processo mais próximos de sua área de conhecimento. O texto finaliza citando o "empenho entre parceiros" como condição para atingir os resultados no exíguo tempo (45 dias) que fora definido como prazo para a inauguração do CCP. Nesse ponto, verifica-se que o autor do relatório aponta, sem muita ênfase, o trabalho coletivo como um importante elemento na conformação dos resultados da iniciativa.

Nesse documento, também é apresentado um relatório fotográfico do evento de inauguração, ilustrando cada um dos parceiros representados pelas suas maiores instâncias: os presidentes da Eletrobras e da Emater e o diretor da CERJ. A participação de gestores que ocupam posições-chave é registrada no relatório, levando a supor que a instalação desse CCP carrega uma importância política bastante significativa para tais instituições. Mais precisamente, a inauguração do primeiro projeto de CCP da Eletrobras, vinculado a um programa de universalização de energia (Programa Luz no Campo), parece significar para os financiadores um bom dispositivo para a promoção das respectivas imagens institucionais.

O documento não apresenta qualquer perspectiva que se relacione de forma mais sistemática com os elementos que cercam o conceito de capital social. De fato, trata-se de um relatório, redigido como um documento de prestação de contas, menos propenso, portanto, a discussões voltadas para aspectos relativos ao ordenamento social que cerca o CCP.

$\mathrm{O}$ quarto documento analisado foi produzido em janeiro de 2004. Trata-se de um informativo mensal de veiculação interna, criado pelo Departamento de Comunicação da Eletrobras para os seus empregados. Nessa edição de número 87, é apresentada uma matéria completa sobre a inauguração do primeiro CCP da Eletrobras, situado em de São Fidélis.

$\mathrm{O}$ informativo relata, dentre outras coisas, a presença do presidente da Eletrobras no evento e cita o papel de cada parceiro para a viabilização do projeto. Também chama a atenção para a rapidez com que foi construído o espaço físico do CCP (45 dias), que abriga os equipamentos de resfriamento de leite.

$\mathrm{O}$ documento cita que a associação dos produtores de Boa Esperança se encarregou de parte da mão de obra, do material de construção e da alimentação dos trabalhadores. Isso demonstraria a participação efetiva dos agricultores desde o início do processo. No texto, verifica-se um discurso que não se limita a tratar o CCP apenas pela via da geração de renda, pois este é visto, também, como um dispositivo que fomenta a participação: "O Centro Comunitário de Produção de Boa Esperança foi concebido para resgatar e consolidar entre os produtores de São Fidélis um valor indispensável para o desenvolvimento da microeconomia rural: o associativismo" (Informativo Eletrobras n ${ }^{\circ} 87$, jan/2004).

Outra seção do informativo apresenta uma entrevista com representantes de cada um dos parceiros que atuaram na implantação do CCP (Eletrobras, CERJ, Prefeitura Municipal e Associação de Produtores e Moradores de Boa Esperança). Nessa sessão, é destacada a ideia de que a "Parceria é alma do negócio". No caso da Eletrobras, a fala do presidente atrela o projeto do $\mathrm{CCP}$ ao programa de universalização do fornecimento de energia elétrica e prevê o apoio para a inauguração de muitos outros centros em todo o país. 
O informativo expõe um discurso entusiasmado do presidente ressaltando a necessidade de levar ao "homem do campo", além de energia elétrica, formas de utilizar tal insumo para "melhorar suas condições de trabalho e aumentar sua renda" (Informativo Eletrobras n ${ }^{\circ} 87$, jan/2004). No desfecho de sua entrevista, o presidente certifica que aquela seria a primeira de muitas outras iniciativas de CCP que se seguiriam. A exposição no informativo do discurso do presidente nos leva a refletir sobre o que teria acontecido para que o projeto enfrentasse tantas dificuldades para se consolidar, apesar do apoio inicial que o mesmo parecia receber por parte da instituição.

Já o representante do setor privado, diretor de relações institucionais da concessionária CERJ (atual AMPLA), apresenta em sua fala um parecer bastante favorável à iniciativa, indicando que sua empresa e seus acionistas teriam "grande interesse em multiplicar essa iniciativa", cumprindo, dessa forma, "seu papel social de fomentar o desenvolvimento". Trata-se de um posicionamento bastante relacionado aos negócios, voltado para a preocupação com as ligações de novos pontos e a manutenção do programa de universalização. No entanto,verificou-se que, após a inauguração do CCP de São Fidélis, poucos outros CCPs foram apoiados novamente por aquela empresa.

A esfera estadual pronunciou-se por meio do presidente da Emater-RIO. Sua visão aponta para o distanciamento entre as instituições parceiras e os agricultores familiares. Na transcrição do discurso, percebe-se a ênfase maior na integração das três esferas governamentais, como se a parceria para a implantação do CCP fosse estabelecida somente entre as instituições públicas, esquecendo-se do setor privado e dos agricultores familiares.

O representante da Emater aponta que foi positivo observar o presidente da Eletrobras cumprimentando e sendo cumprimentado por "homens do campo". O simbolismo dessa fala reve- la, por um lado, a aproximação entre o poder federal (representado pelo gestor máximo da Eletrobras) e uma parcela pauperizada da população, para o estabelecimento de uma relação de parceria. Por outro lado, também expressa a ideia - advinda da surpresa daquele que observa a ação - de que distintas camadas sociais não se articulam, não negociam e não se integram, ou seja, de que tais relações tendem a ocorrer de maneira mais verticalizada.

Esse mesmo representante aponta que a valorização das áreas rurais ocorre "evidentemente, pela geração de emprego e renda" (Informativo Eletrobras $\left.\mathrm{n}^{\mathrm{0}} 87, \mathrm{jan} / 2004\right)$. Nesse momento, faz uma defesa do associativismo: "Sabemos que o pequeno produtor só tem chance de melhorar sua qualidade de vida enquanto faz parte de um movimento associativo e, de forma mais avançada, quando chega a um movimento cooperativista" (Informativo Eletrobras $\mathrm{n}^{\mathrm{o}} 87$, jan/2004).

Contudo, o discurso do representante da Emater refere-se, também, ao fato de que os órgãos e as instâncias públicas ali presentes haviam doado para a comunidade os equipamentos, as instalações e o saber técnico necessário à execução do CCP. Nessa concepção, o agricultor familiar aparece como um coadjuvante, na medida em que não é considerado um importante elemento da parceria, reforçando a ideia de que o projeto é pautado por uma perspectiva de implementação vinda de cima para baixo.

Esta citação demonstra tal visão verticalizada: "no momento em que proporcionamos a esse produtor uma oportunidade como essa [de ter um CCP], estamos transmitindo a ele a seguinte mensagem: pratique $\mathrm{o}$ associativismo, porque você ficará mais forte, será apoiado, e terá o respeito e a atenção do setor público" (Informativo Eletrobras $n^{\circ} 87$, jan/2004).

Por fim, o informativo apresenta a perspectiva do prefeito do município, que chama atenção para os ganhos que o 
agricultor familiar, enquanto indivíduo localizado em um ambiente específico (o meio rural) e auxiliado pela infraestrutura do $\mathrm{CCP}$, poderia obter, sendo possível, assim, manter-se "na própria terra, com dignidade, sem precisar mendigar emprego nas cidades" (Informativo Eletrobras n ${ }^{\circ} 87, \mathrm{jan} / 2004$ ).

Quando o prefeito se refere à parceria, sugere a ideia de "unificação", de "participação de todos" e de "horizontalidade", enfatizando a soma de conhecimentos como um aspecto muito importante que teria proporcionado a implementação do CCP: "Mas o principal é a gestão do CCP pelos próprios produtores - sobretudo os menores, que estão desenvolvendo a autoestima e aprendendo a negociar com as cooperativas. Hoje eles se sentem donos do próprio negócio e começam a resgatar a essência do cooperativismo, que vinha se perdendo nos últimos tempos" (Informativo Eletrobras $\left.n^{\circ} 87, j a n / 2004\right)$. Segundo o informativo, o prefeito finalizou sua fala ratificando a necessidade de associativismo: "Os pequenos produtores estão percebendo que, para progredirem, precisam se unir, se libertar dos intermediários que só querem vantagens financeiras e políticas, e aprender, no dia a dia, a administrar o seu negócio" (Informativo Eletrobras $\mathrm{n}^{\mathrm{o}}$ 87, jan/2004).

A criação de organizações e a consolidação das relações de confiança entre os indivíduos são apregoados por Putnam (2007) como elementos componentes do capital social. Para que haja o cooperativismo, é necessário que se exercite a troca de confiança entre os produtores - a elevação da autoestima fará com que esses indivíduos busquem expressar seus anseios na participação da gestão do CCP e se colocar ainda mais em relação aos anseios do outro.

Essa troca vai gerar negociação, e, para que os agricultores possam ter suas expectativas minimamente atendidas, haverá necessidade de confiança mútua no que tange aos acordos a serem cumpridos. As regras de reciprocidade citadas por Putnam (2007) encontram solo fértil nessa concepção de atuação a que se propõe o projeto dos CCPs; sejam estas "específicas" (permuta simultânea de itens de igual valor) ou "generalizadas" (um favor concedido em um dado momento será retribuído em algum momento futuro).

Todo o texto, inclusive a síntese elaborada pelo Departamento de Comunicação da Eletrobras, que foi o autor do informativo, expressa a preocupação em citar o associativismo e relacioná-lo à sustentabilidade. A ideia de organização, defesa de interesses, coletividade e associativismo, apresentada como um retorno ou como algo necessário para que um CCP se constitua, perpassa todo o documento e aparece em todos os discursos transcritos. É importante observar que esse documento de circulação interna institucional divulga o conceito de CCP e o coloca na pauta de discussão cotidiana, pelo menos dos empregados da Eletrobras, não como um projeto exclusivamente voltado para a geração de trabalho e renda, mas como fomentador de relações associativas. Aqui percebemos, ao longo do processo de consolidação do projeto, que o desenho do $\mathrm{CCP}$ - ainda que não necessariamente formalizado - vai progressivamente apontando para elementos que fazem parte do rol de preocupações do conceito de capital social, tal como definido em Putnam (2007).

$\mathrm{O}$ quinto documento analisado aqui corresponde a uma matéria jornalística publicada em $1^{\circ}$ e junho de 2005 , cujo título é: "Uma cidade que transita da seca ao sonho". Trata-se de um documento publicado na internet pelo Conselho Nacional de Secretários Municipais de Saúde (Conasems) ${ }^{7}$.

$\mathrm{O}$ documento refere-se ao município de Pintadas, Bahia, onde a Eletrobras, posteriormente, implantou um projeto de CCP. O repórter busca en-

Esse documento foi analisado a partir de um material impresso, capturado em 01/06/2005 em [http://www.conasems.org.br/mostraPagina. asp?codServico=35\&codPagina=22], que não se encontra mais ativo. 
tender como uma cidade castigada pela seca e com poucos incentivos governamentais, considerada uma das mais pobres do estado da Bahia, conseguiu ganhar um prêmio de melhores práticas em gestão local.

A matéria aponta que quase $60 \%$ da população vivia em pequenos povoados na zona rural divididos em comunidades - palavra que, segundo o autor, tem um valor histórico naquele município - e que a prefeita eleita em 1996 e reeleita em 2000 chegou à cidade na década de 1980 como missionária. Esta incentivou a criação de associações comunitárias, de sindicatos e de cooperativas e a participação da igreja católica na formação da Rede Pintadas (projeto que envolve grande parte da população, por meio de movimentos sociais, atuando junto ao poder local na implementação de ações de geração de emprego e renda, abastecimento de água e qualificação profissional).

O texto, citando a fala da secretária municipal de saúde, apresenta uma comunidade engajada, com elevado senso de participação. O município realizou um trabalho com o departamento de medicina da Universidade Federal da Bahia (UFBA) que, em parceria com as lideranças comunitárias, visitou povoados, preparou diagnóstico e auxiliou na formação de multiplicadores de saúde.

A apresentação dos resultados para a comunidade levou à conscientização de que a questão da saúde ultrapassava os episódios de doença. Nesse sentido, a prevenção e a mudança de comportamento frente às questões básicas deveriam ser entendidas pela população como fundamentais para uma boa qualidade de vida. Segundo a secretária de saúde, "graças ao empenho da população, a implantação destas práticas quebrou o vínculo doente -político, que dominava a saúde pública de Pintadas" (Conasems, 2005). Ou seja, as mudanças na saúde em Pintadas ocorreram por conta da própria motivação popular, manifestada em abaixo-assinados e passeatas.
Nesse contexto, a atuação de movimentos como o de mulheres, bem como a conscientização da população como um todo, propiciou o cerceamento de práticas clientelistas de favorecimento, que tendem a fortalecer o indivíduo em detrimento da coletividade. Segundo a matéria, Pintadas preferiu buscar desenvolver práticas cívicas, investindo no diálogo com a população, trazendo o cidadão para a mesa de negociação e gerando um capital crítico, participativo e comprometido com o coletivo. O documento finaliza afirmando que "O nascimento de Pintadas se confunde com a história de uma organização social de caráter popular, cuja luta levou à conquista do poder público municipal" (Conasems, 2005).

O sexto documento analisado refere-se a um projeto apresentado em 12 de agosto de 2005 à Eletrobras pela Cooperativa Agroindustrial de Pintadas (COOAP), pleiteando a construção de um CCP para incremento da atividade leiteira. $\mathrm{O}$ documento, baseado nas orientações do manual de CCP da Eletrobras, inicia fazendo uma contextualização do município onde estaria situada a comunidade demandante do projeto. Dessa forma, apresenta uma série de indicadores sociais para justificar a necessidade de apoio. Baseado em dados do Instituto Brasileito de Geografia e Estatística (IBGE), o documento trata de uma comunidade tipicamente rural $(63,8 \%)$ e com baixos índices sociais: Índice de Custo de Vida (ICV) de 0.472; Índice de Desenvolvimento Humano (IDH) de 0.620; e Índice de Desenvolvimento Infantil (IDI) de 0.366 .

Relata, também, os problemas relacionados à migração rural-urbana decorrente da concentração fundiária e da escassez de emprego, forçando a saída de homens para o Sudeste para trabalhar nas usinas de álcool do interior de São Paulo, deixando a cargo das mulheres todas as responsabilidades concernentes à vida familiar. $\mathrm{O}$ documento salienta, assim, uma situação geradora de desequi- 
líbrio de gênero, impactando o conjunto da sociedade local. Informa, ainda, que a economia de Pintadas sofreu uma crise nos anos 1999/2000, quando perdeu seus principais canais de comercialização de leite (Nestlé e Parmalat), por não possuir uma produção suficiente que justificasse investimento em inovações por parte do setor privado.

O documento cita que, em decorrência dessa crise, os produtores familiares buscaram alternativas para se manter na atividade rural. Passaram, então, a vender o leite para a Cooperativa Central de Laticínios da Bahia (CCLB) (uma empresa estatal), além de fornecer o produto para algumas pequenas fábricas de requeijão situadas em comunidades vizinhas. Embora não fique evidente, o projeto sugere que os agricultores familiares buscaram soluções para resolver a crise que os atingia.

Isso revela que em Pintadas já existia um espírito comunitário de busca de soluções, que possibilitava ações da sociedade civil independentes do poder local e que tendiam para a cooperação. Percebe-se, dessa forma, um potencial para o sucesso do CCP, pois já poderia ser identificado um dos elementos necessários para a sua boa configuração, que é a participação comunitária.

Reforçando esse ponto, o documento passa então a discorrer sobre as experiências de associações do município na produção agrícola e na condução de assuntos coletivos. Diferentemente do que preconiza Putnam (2007) acerca da verticalidade da igreja católica, que tende a hierarquizar as relações, dificultando as regras de reciprocidade, solidariedade, participação e comportamento cívico, em Pintadas, foi por meio dessa entidade religiosa, representada pelas comunidades eclesiais de base, que a comunidade passou a refletir sobre seus problemas - não por meio de uma avaliação fatalista (do tipo "tudo se deve a Deus"), mas com uma perspectiva de conscientização de seus direitos e deveres enquanto cidadãos.
Essa conscientização promovida pela igreja gerou, de início, um movimento de luta pela terra. O Partido dos Trabalhadores (PT) assumiu o executivo municipal em 1996, e, segundo o documento analisado, havia uma sinergia muito forte entre os elementos político-partidários e os elementos sociais $\mathrm{e}$ comunitários - o que revelava uma forte comunhão entre interesses públicos e coletivos. De fato, a Rede Pintadas correspondia a uma "tecnologia social ${ }^{8}$ " que operacionalizava essa relação.

O texto do projeto apresenta ganhos como a CrediPintadas, atual SICOOB Sertão, que é uma cooperativa de crédito conquistada com a ajuda da prefeitura, responsável pela gestão financeira de recursos que eram repassados por parceiros externos às instituições integrantes da Rede. Essa foi uma conquista ocorrida após a perda do apoio do Banco do Estado da Bahia (BANEB) que fechou as portas na cidade quando o PT ganhou as eleições no município.

$\mathrm{O}$ documento analisado preocupa-se em demonstrar que a cidade respirava relações de cooperativismo e associativo e que esses eram os pilares para a solução das crises e para o desenvolvimento do município. $\mathrm{O}$ documento cita, também, as parcerias estabelecidas com instituições nacionais e internacionais a fim de financiar projetos por meio da Rede Pintadas.

É destacado, ainda, que Pintadas contava com o Centro Comunitário de Serviços de Pintadas (CCSP), um dispositivo social que buscava apoio de fontes externas tanto financeiras como técnicas para a criação de alternativas à geração de emprego e renda e de formas de produção e convivência com a seca. No CCSP, estava sediada a Rede, onde se desenvolviam as inter-relações entre as instituições integrantes. Finalizando, o texto apresenta o público-alvo e as justificativas para a implantação de um CCP para resfriamento de leite no município,

8 Compreendem produtos, técnicas ou metodologias reaplicáveis, desenvolvidas na interação com a comunidade e que representam efetivas soluções de transformação social. 
citando, por exemplo, a necessidade de atender às exigências do Ministério da Agricultura em relação ao transporte do leite e os benefícios que os agricultores familiares poderiam obter.

$\mathrm{O}$ sétimo e último documento avaliado data de 26 de maio de 2006. Refere-se a um relatório para a apreciação da diretoria executiva (que é responsável por homologar os projetos em que a Eletrobras deseja atuar). Esse relatório tem como objetivos a institucionalização dos Projetos Complementares às obras do Programa Luz para Todos, do Programa de criação e consolidação de CCPs e do Programa de Avaliação do Desempenho de Equipamentos Eletrorrurais (PADEE).

Trata-se de um relatório cuja origem estava nas diretorias de Engenharia, Projetos Especiais e Administração. $\mathrm{O}$ documento encaminhado à diretoria executiva tratava de dois programas, sendo um deles o projeto de CCP. Como argumento de convencimento para a proposta de execução do projeto, o documento utiliza a experiência do primeiro CCP da Eletrobras, o de São Fidélis. $\mathrm{O}$ documento cita que a experiência foi tão exitosa que outras concessionárias e outros órgãos de extensão rural vinham apresentando novos pleitos.

$\mathrm{O}$ discurso do relatório fundamenta-se na possibilidade dessas novas comunidades, que passaram a receber energia elétrica, poderem ter, além de conforto, a energia enquanto vetor de desenvolvimento, agregando valor à produção agrícola e favorecendo o aumento da renda. O objetivo do documento era consolidar os CCPs, atribuindo poder ao Departamento de Gestão do Programa de Universalização (DEP), para desenvolvê-lo institucionalmente, e também garantir a destinação de recursos financeiros ao projeto.

O documento também objetiva demarcar papéis entre departamentos, de forma que projetos da DEP e do Departamento de Responsabilidade Social (DAS) não se sobrepusessem em uma mesma comunidade. No texto, o projeto é constantemente citado como uma ação complementar para possibilitar que o agricultor familiar que passa a ter acesso à eletricidade pudesse fazer uso desta de maneira produtiva, gerando renda e melhorando as condições de vida de sua família - e, ao mesmo tempo, garantindo os recursos necessários para o pagamento do seu consumo de energia. Com isso, a empresa cumpriria seu papel social, fomentaria um mercado rural de energia e preveniria a inadimplência para as concessionárias, gerando formas para que o novo consumidor pudesse pagar sua conta.

Esse relatório que analisamos constitui um documento de caráter mais político, voltado para a institucionalização do projeto, buscando definir as responsabilidades e legitimar seus agentes formuladores dentro da empresa. Nesse sentido, não encontramos argumentos que se relacionem com conceitos de capital social, mas verificamos uma grande ênfase ao fato de que o CCP produziu impactos positivos e significativos para os agricultores familiares beneficiados em São Fidélis.

\section{Considerações finais}

Iniciamos nosso trabalho indicando uma série de questões que deveriam ser observadas na análise dos sete documentos aqui avaliados. Em cada uma dessas análises, foi possível verificar uma série de elementos que nos conduziram para uma leitura acerca do posicionamento institucional do projeto dos CCPs ao logo do tempo. Buscou-se apresentar tais documentos sob a forma de uma trajetória, para que ficassem claras as mudanças temporais no desenho implícito e explícito do projeto.

Partimos, dessa forma, de uma questão principal fundamentada no conceito de capital social, tal como utilizado por Putnam (2007). Na análise, tentamos verificar se elementos que Putnam (2007) considera formadores 
de capital social estavam, de alguma forma, presentes nos diversos textos dos documentos analisados. Para atingirmos a questão central, uma série de questões mais específicas foram definidas e nos ajudaram a compreender o reconhecimento institucional atribuído ao projeto e os discursos utilizados para a sua institucionalização.

Pudemos verificar, assim, ao longo das análises, que o projeto nasceu para resolver um impasse relacionado à possível inadimplência por parte dos novos consumidores de energia elétrica no meio rural que estavam sendo incorporados às redes de fornecimento. Ou seja, o benefício da eletricidade que chegara trazia consigo um custo associado que precisava ser pago. O projeto de CCP é proposto, então, como solução para esse problema. A ideia era que a produção agrícola coletiva fosse fomentada por meio de investimentos capazes de gerar formas de agregação de valor aos produtos da agricultura familiar, que poderiam, a partir daí, alcançar mercados mais robustos.

No entanto, no contexto dessa proposta, percebe-se que a geração de renda através do CCP pode ocorrer em um ambiente capaz de desenvolver relações de confiança e incremento da participação comunitária. Tais aspectos seriam capazes de fazer com que as comunidades ampliassem suas potencialidades, buscando novos projetos, parcerias e financiamentos, desenvolvendo novas vocações e sendo, enfim, protagonistas de seu próprio futuro socioeconômico.

Ao exigir que as comunidades se organizem em associações, a Eletrobras tangencia um dos elementos que Putnam (2007) considera fundamental para a formação do capital social. Embora na origem do projeto essa não fosse a preocupação principal, marginalmente ela vai se conformando e dando mais sustentabilidade à proposta.

Os elementos que, segundo Putnam (2007), seriam propulsores de capital social são introduzidos em quase to- dos os documentos aqui analisados - seja de forma explícita ou implícita. Mesmo em matérias informativas, de veiculação interna da empresa, os CCPs são apresentados como projetos que, além de gerar renda, transformam realidades sociais em direção à formatos de protagonismo associativo local, impulsionando indivíduos e grupos a buscarem mudanças por meio da confiança e da participação.

\section{Referências}

1. Cooperativa Agroindustrial Pintadas Ltda. Centro Comunitário de Produção do Sertão no Município de Pintadas - Bahia. COOAP. Agosto 2005.

2. Departamento Intersindical de Estatística e Estudos Socioeconômicos. Índice do custo de Vida. 2014. Disponível em [http://www.dieese.org.br/ analiseicv/icv.html]

3. Eletrobras. Luz no Campo - Projetos Sustentáveis Proposta de Projeto. Minuta. Diretoria de Engenharia - Departamento de Engenharia de Distribuição, Janeiro 2003.

4.

Manual para Apresentação de Projeto de Centro Comunitário de produção (CCP). Diretoria de Engenharia - Departamento de Engenharia de Distribuição, Julho 2003.

5. Centro Comunitário de Produção São Fidelis. Relatório Eletrobras. Diretoria de Engenharia - Departamento de Engenharia de Distribuição, Janeiro 2003.

6. Informativo da Centrais Elétricas Brasileiras S.A. - Eletrobras. Departamento de Comunicação social - PRC, Janeiro 2004.

7. Flick, U. Introdução à pesquisa qualitativa / Uwe Flick; tradução Joice Elias Costa. - 3. Ed. - Porto Alegre: Artmed, 2009.

8. Fundação Banco do Brasil. Tecnolo- 
gia social. 2014. Disponível em [http:// www.fbb.org.br/tecnologiasocial/o-que -e/tecnologia-social/]

9. Presidência da República. Casa Civil. Subchefia para Assuntos Jurídicos. DECRETO DE 2 DE DEZEMBRO DE 1999. Disponível em [http://www. planalto.gov.br/ccivil 03/DNN/Anterior\%20a\%202000/1999/Dnn8715. $\mathrm{htm}]$

10. Programa da Nações Unidas para o Desenvolvimento. Desenvolvimento humano e IDH. 2014. Disponível em [http://www.pnud.org.br/IDH/DH.as$\mathrm{px}]$

11. Putnam, R. D. Comunidade e democracia: a experiência da Itália moderna. / Robert D. Putnam, com Robert Leonardi e Raffaella Y. Nanetti; tradução Luiz Alberto Monjardim. - reimpressão. - Rio de Janeiro: Editora FGV, 2007.

12. Scott, J. A Matter of Record - Documentary Sources in Social Research. Cambridge: Polity. 1990.

13. Tocqueville, A. de. A democracia na América. São Paulo, Martins Fontes, 2004.

14. Unicef - Brasil. Índice de Desenvolvimento Infantil. 2014. Disponível em [http://www.unicef.org/brazil/pt/activities_10175.htm] 